\title{
Prevention and treatment of pressure ulcers by newest recommendations from European Pressure Ulcer Advisory Panel (EPUAP): practical reference guide for GPs
}

\author{
JAKUB TARADAJA-G \\ Academy of Physical Education in Katowice \\ Trustee of EPUAP
}

A - Study Design, B - Data Collection, C - Statistical Analysis, D - Data Interpretation, E - Manuscript Preparation, F - Literature Search, G - Funds Collection

Summary The guideline titled "Prevention and treatment of pressure ulcers: clinical practice guideline" is the result of a collaborative effort between the National Pressure Ulcer Advisory Panel (NPUAP), European Pressure Ulcer Advisory Panel (EPUAP) and Pan Pacific Pressure Injury Alliance (PPPIA). A comprehensive literature review was conducted on pressure ulcer prevention and treatment. Rigorous scientific methodology was used to appraise available research and make evidence-based recommendations for the prevention and treatment of pressure ulcers. Draft guidelines were made available to 986 invited individual stakeholders and organizations or societies, and the feedback of the stakeholders was taken under consideration by the developers of the guideline. The guideline includes 575 explicit recommendations and/or research summaries for multidisciplinary pressure ulcer topics.

Key words: guideline, pressure ulcer, clinical practice.

Taradaj J. Prevention and treatment of pressure ulcers by newest recommendations from European Pressure Ulcer Advisory Panel (EPUAP): practical reference guide for GPs. Fam Med Prim Care Rev 2017; 19(1): 81-83, doi: 10.5114/fmpcr.2017.65097.

\section{Background}

The newest edition of "Prevention and treatment of pressure ulcers: clinical practice guideline" presents recommendations and summarizes the supporting evidence for pressure ulcer prevention and treatment and was published in 2014 [1]. This guideline is the result of a collaborative effort between the National Pressure Ulcer Advisory Panel (NPUAP), European Pressure Ulcer Advisory Panel (EPUAP) and Pan Pacific Pressure Injury Alliance (PPPIA). Rigorous scientific methodology was used to appraise available research and make evidence-based recommendations for the prevention and treatment of pressure ulcers. Draft guidelines were made to available to 986 invited individual stakeholders and organizations or societies, and the feedback of the stakeholders was taken under consideration by the developers of the guideline. The author of this short report in the journal Family Medicine \& Primary Care Review as a "trustee", and one of the members of the Scientific \& Guideline Committee of the European Pressure Ulcer Advisory Panel (EPUAP) were permitted to participate in preparing the newest edition and took part in two Small Working Groups (SWC), titled "Emerging therapies for prevention" and "Biophysical agents for treatment". In the final development process, the guideline team used a consensus voting process (GRADE) to assign the strength of recommendations. The strength of recommendations indicate the extent to which one can be confident that adherence to a recommendation will do more good than harm and are indented to assist the health professional (general practitioners as well) to prioritize interventions. The guideline includes 575 explicit recommendations and/or research summaries for the following pressure ulcer topics: etiology; prevalence and incidence; risk assessment; skin and tissue assessment; preventive skin care; prophylactic dressings; microclimate control; fabrics and textiles; nutrition; repositioning and early mobiliza- tion; support surfaces; medical device related pressure ulcers; pressure ulcer classification; wound assessment; monitoring of healing; pain assessment and treatment; cleansing; debridement; wound dressings (including growth factors and biological wound dressings); infection and biofilms; biophysical agents (e.g. electrical stimulation, negative pressure wound therapy, electromagnetic fields); and surgery.

\section{Guideline Website}

A Quick Reference Guide [2] (brief version of the complete document) is freely available through a link provided on the EPUAP website: http://www.epuap.org/guidelines/quick-reference-guide-2014-edition-translations/.

\section{Participants}

All members of the development team were screened for experience, expertise and potential conflicts of interest. In the interest of transparency, all guideline developers were asked to complete a form identifying potential conflicts of interest, which covered the guideline review period. The Guideline Development Group (GDG) determined and monitored each step of the process, as well as managing guideline strategy. Each of the three partner organizations nominated four representatives each to form the twelve members of the GDG. From its nominated representatives, each partner organization appointed a Chair. Examinations of the evidence and consensus building preceded all voting. The guideline content was divided into working topic areas, and Small Working Groups (SWG) were formed to review the evidence available for each topic. The members of the SWG were selected by each participating organization based on experience and expertise. Guideline development was an interactive process, with GDG and SWG members 


\begin{tabular}{|l|l|}
\hline \multicolumn{2}{|l|}{ Table 1. Level of evidence } \\
\hline Level 1 & $\begin{array}{l}\text { Randomized trial(s) with clear-cut results and low risk of error OR systematic review OR meta-analysis according to the } \\
\text { Cochrane methodology or meeting at last } 9 \text { out of } 11 \text { quality criteria according to the AMSTAR appraisal tool }\end{array}$ \\
\hline Level 2 & Randomized trial(s) with uncertain results and moderate to high risk of error \\
\hline Level 3 & Non randomized trial(s) with concurrent or contemporaneous controls \\
\hline Level 4 & Non randomized trial(s) with historical controls \\
\hline Level 5 & Case series with no controls. Specify number of subjects \\
\hline
\end{tabular}

\section{Table 2. Strength of evidence}

\begin{tabular}{|l|l|}
\hline A & $\begin{array}{l}\text { The recommendation is supported by direct scientific evidence from properly designed and implemented controlled trials } \\
\text { on pressure ulcers in humans (or individuals at-risk for pressure ulcers), providing statistical results that consistently support } \\
\text { the guideline LEVEL } 1 \text { is required }\end{array}$ \\
\hline B & $\begin{array}{l}\text { The recommendation is supported by direct scientific evidence from properly designed and implemented clinical series on } \\
\text { pressure ulcers in humans (or individuals at-risk for pressure ulcers), providing statistical results that consistently support } \\
\text { the guideline LEVEL } 2,3,4 \text { of studies }\end{array}$ \\
\hline C & $\begin{array}{l}\text { The recommendation is supported by indirect evidence (e.g. studies in normal human subjects, human with other types of } \\
\text { chronic wounds, animal models) and/or expert opinion }\end{array}$ \\
\hline
\end{tabular}

\begin{tabular}{|c|c|}
\hline Recommendation for GPs & Description \\
\hline $\begin{array}{l}\text { Do it } \\
\text { (strong recommendation for using an intervention) }\end{array}$ & \multirow[t]{2}{*}{ Indicates a judgment that most well-informed individuals would make } \\
\hline $\begin{array}{l}\text { Do not do it } \\
\text { (strong recommendation against using an intervention) }\end{array}$ & \\
\hline $\begin{array}{l}\text { Probably do it } \\
\text { (weak recommendation for using an intervention) }\end{array}$ & \multirow[t]{2}{*}{$\begin{array}{l}\text { Indicates a judgment that the majority of well-informed individuals would make, } \\
\text { but a substantial minority would not }\end{array}$} \\
\hline $\begin{array}{l}\text { Probably do not do it } \\
\text { (weak recommendation against using an intervention) }\end{array}$ & \\
\hline No specific recommendation & $\begin{array}{l}\text { Trade-offs between risk and benefit unclear or lack of agreement between vot- } \\
\text { ing specialists }\end{array}$ \\
\hline
\end{tabular}

maintaining communication via the methodologist (who also managed the confidential consensus voting process).

\section{Methods}

To identify scientific literature on pressure ulcer prevention and treatment, several electronic databases were consulted, including: PubMed, CINAHL, Medline, Embase, Scopus, Biomedical Reference Collection, Health Business Elite, The Cochrane Database of Systematic Reviews, The Cochrane Central Register of Controlled Trials, Health Technology Assessment and AMED databases. All references retrieved by the electronic literature search were screened by the team (for a period over ten years) based on the following eligibility criteria (inclusion and exclusion criteria). The "level of evidence" for individual studies was noted for each article containing direct evidence, using a classification system (Table 1). "Strength of evidence" ratings were assigned to recommendations. This rating identifies the strength of a cumulative body of evidence supporting each indication (Table 2). The final review and recommendations resulted in five potential orders (Table 3 ).

\section{Sample of results from the presented guideline}

It is not possible to discuss all recommendations from the pressure ulcer guideline in the following paper. However, the most important group of indications for GPs is below (some may be controversial when compared to common medical knowledge - especially that which is specialized or not scientific):

- Preventive Skin Care: avoid positioning the individual on an erythema whenever possible (strength of evidence $=\mathrm{C}$; definitely do it); keep the skin clean and dry (strength of evidence $=\mathrm{C}$; definitely do it); use a $\mathrm{pH}$ balanced skin cleanser (strength of evidence $=\mathrm{C}$; definitely do it); do not massage or vigorously rub skin that is at risk of pressure ulcers (strength of evidence = B; probably do it); cleanse the skin promptly following episodes of incontinence (strength of evidence $=C$; definitely do it); protect the skin from exposure to excessive moisture with a barrier product in order to reduce the risk of pressure damage (strength of evidence = C; probably do it); consider using a skin moisturizer to hydrate dry skin in order to reduce risk of skin damage (strength of evidence = C; probably do it); do not use dimethyl sulfoxide (DMSO) for the prevention of pressure ulcers (strength of evidence $=\mathrm{B}$; definitely do it).

- Nutrition in pressure ulcer prevention and treatment: protein intake (strength of evidence $=\mathrm{B}$; probably do it); hydration (strength of evidence = $\mathrm{C}$; definitely do it); vitamins and minerals (strength of evidence $=\mathrm{B}$; definitely do it).

- Wound dressings for treatment of pressure ulcers: hydrocolloid dressings (strength of evidence $=B$; probably do it); transparent film dressings (strength of evidence $=\mathrm{C}$; probably do it); hydrogel dressings (strength of evidence $=\mathrm{C}$; definitely do it); (strength of evidence = C; probably do it); alginate dressings (strength of evidence $=\mathrm{C}$; probably do it); foam dressings (strength of evidence $=\mathrm{C}$; probably do it); silver-impregnated dressings (strength of evidence $=\mathrm{B}$; definitely do it); (strength of evidence $=\mathrm{B}$; probably do it); honey impregnated dressings (strength of evidence $=C$; no specific recommendation); silicone dressings (strength of evidence $=\mathrm{C}$; probably do it); collagen matrix dressings (strength of evidence $=\mathrm{C}$; no specific recommendation); biological dressings (strength of evidence = C; no specific recommendation). 
- Growth factors for the treatment of pressure ulcers: recombinant platelet-derived growth factor (strength of evidence = B; no specific recommendation).

- Biophysical agents in pressure ulcer treatment: electrical stimulation (strength of evidence $=A$; probably do it); electromagnetic fields (strength of evidence $=\mathrm{C}$; no specific recommendation); laser therapy (strength of evidence $=\mathrm{C}$; no specific recommendation); ultrasound therapy (strength of evidence $=\mathrm{C}$; no specific recommendation); negative pressure wound therapy (strength of evidence $=\mathrm{B}$; definitely do it); hyperbaric oxygen therapy (strength of evidence $=\mathrm{C}$; no specific recommendation).

Source of funding: The European Pressure Ulcer Advisory Panel funds (grant no. 1066856).

Conflict of interest: The authors declare no conflict of interests.

\section{References}

1. National Pressure Ulcer Advisory Panel, European Pressure Ulcer Advisory Panel and Pan Pacific Pressure Injury Alliance: Prevention and Treatment of Pressure Ulcers: Clinical Practice Guideline. Perth, Australia: Cambridge Media 2014.

2. National Pressure Ulcer Advisory Panel, European Pressure Ulcer Advisory Panel and Pan Pacific Pressure Injury Alliance: Prevention and Treatment of Pressure Ulcers: Quick Reference Guide. Perth, Australia: Cambridge Media; 2014.

Tables: 3

Figures: 0

References: 2

Received: 10.07 .2016

Revised: 13.07.2016

Accepted: 13.07 .2016

Address for correspondence:

Prof. Jakub Taradaj, PhD

Katedra Podstaw Fizjoterapii AWF

ul. Mikołowska $72 \mathrm{~A}$

40-065 Katowice

Polska

Tel.: +48 668 613-945

E-mail: j.taradaj@awf.katowice.pl 